\title{
Two cases of juvenile hypertrophic cardiomyopathy presenting with marked bi-atrial enlargement on standard 12-lead electrocardiogram*
}

\section{Hajime Kataoka}

Division of Internal Medicine, Nishida Hospital, Oita, Japan

Email: hkata@cream.plala.or.jp

Received 19 September 2011; revised 8 November 2011; accepted 18 November 2011

\begin{abstract}
This report describes two cases of juvenile hypertrophic cardiomyopathy (HCM) in which prominent bi-atrial enlargement was observed on standard 12lead electrocardiogram, suggesting inherent predisposition to extreme enlargement and/or hypertrophy may exist in atrial myocardium in juvenile HCM. Comparative study between juvenile and adult HCM patients using a large sample size is required to confirm this hypothesis.
\end{abstract}

Keywords: Hypertrophic Cardiomyopathy; Electrocardiogram; P-Wave; Atrial Enlargement

\section{INTRODUCTION}

Previous reports $[1,2]$ indicate that an inverse relation exists between left ventricular hypertrophy and age, and suggest that left ventricular hypertrophy often progresses in juvenile hypertrophic cardiomyopathy (HCM). Progression of atrial enlargement in relation to age has not yet been examined. Here, this report describes two cases of juvenile HCM in which prominent bi-atrial enlargement was observed on 12-lead electrocardiograms (ECG). In this report, the ECGs were interpreted following the criteria described by Savage et al. [3]; notably, the left atrial enlargement was diagnosed if the product of the depth and duration of the negative portion of the P-wave in lead $\mathrm{V}_{1}$ was greater than $-0.03 \mathrm{mV}$-sec [4]. The right atrial enlargement was diagnosed if there were peaked P-waves in leads II and III or $\mathrm{V}_{1,2} \geq 2.5 \mathrm{mV}$ in amplitude.

\section{CASE PRESENTATION}

Case No. 1. A 19-year-old female had been diagnosed as $\mathrm{HCH}$ since the age of 11 years and was taking verapamil. Follow-up clinical, chest x-ray, standard 12-lead ECG and echo-Doppler studies were obtained periodically.

\footnotetext{
"Disclosures: The author has no conflicts of interest to disclose.
}

Gradual bi-atrial enlargement was observed on serial standard 12-lead ECGs. In parallel with this, her New York Heart Association functional class deteriorated from class I at initial visits to class III at recent visits. The 12-lead ECG taken at the age of 19 years (Figure 1) showed a regular sinus rhythm with prominent right (amplitude of the $\mathrm{P}$ initial force $\mathrm{V}_{2}$ lead $=0.5 \mathrm{mV}$ ) and left atrial (Morris index of the $\mathrm{P}$ terminal force $\mathrm{V}_{1}=-0.4$ $\mathrm{mm}$-sec) enlargement, incomplete right bundle branch block and ST-T changes. Echo-Doppler study taken around this period disclosed asymmetric septal hypertrophy $(20 \mathrm{~mm})$ and hypertrophic right ventricular free wall $(10 \mathrm{~mm})$. Left cavity size was normal (end-diastolic

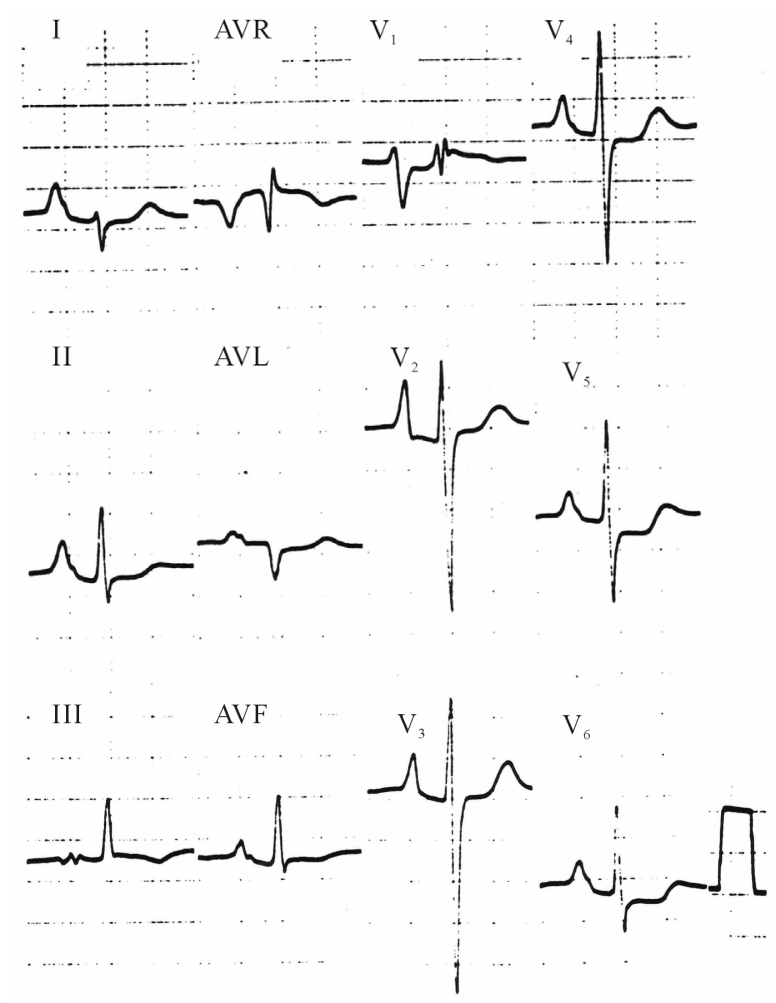

Figure 1. Standard 12-lead ECG of Case No. 1. 
volume of $83 \mathrm{cc}$ ), but the ejection fraction was slightly depressed (51\%). Moderate enlargement of both atria and mild tricuspid regurgitation were noted. Rest thallium201 myocardial scintigram showed marked right ventricular hypertrophy and visualization of the right atrial appendage. Addition of diuretics slightly improved her clinical condition.

Case No. 2. An 18-year-old male had been diagnosed as HCM since the age of 5 years. At the age of 13 years, he developed complete atrio-ventricular block and underwent permanent VVI pacemaker therapy. Serial standard 12-lead ECGs before (a) and after pacemaker therapy (b and c) are shown in Figure 2. At the 3-year follow-up, 12-lead ECG demonstrated gradual enlargement of the right (amplitude of the $\mathrm{P}$ initial force $\mathrm{V}_{1}$ lead $=$ $0.35 \mathrm{mV}$ ) and left atrial (Morris index of the P terminal force $\mathrm{V}_{1}=-0.4 \mathrm{~mm}$-sec) enlargement (Figure 2(b)). In parallel with P-wave abnormalities, progressive heart failure developed and he was admitted twice during this follow-up period. Echo-Doppler study during the convalescent phase demonstrated asymmetric septal hypertrophy $(16 \mathrm{~mm})$ with a slightly dilated (end-diastolic volume of $118 \mathrm{cc}$ ) and moderately hypokinetic (ejection fraction of $45 \%$ ) left ventricle. Both the left and right atria were moderately enlarged. Slight mitral regurgitation and moderate tricuspid regurgitation were detected on Doppler echocardiography. Rest thallium-201 myocardial imaging showed a moderate degree of isotopic uptake in the right ventricle. Medical therapy was not sufficient to improve his clinical condition. Because atrio-ventricular uncoupling due to VVI pacing was considered to be a major contributory factor to congestive heart failure, VVI pacing was switched to dual-chamber pacing, resulting in an improved clinical condition and decrease of the bilateral atrial enlargement on 12-lead ECG (Figure 2(c)).

\section{DISCUSSION}

No previous report has specifically addressed the relation between atrial abnormalities and age in HCM patients. This case presentation of two juvenile HCM patients seems to be important because it was suggested that, beside from the hemodynamic overloading on the right and left atria as the main cause, such ECG findings of prominent atrial enlargement may be induced by factor responsible for the body growth and development characteristics of childhood and adolescence. Previous reports in the literature on adult HCM patients [3,5-8] have not described HCM patients with prominent atrial enlargement on ECG as in the cases reported here. In consecutive 24 adult HCM patients (age, 36 - 80 years; 16 males) that the author has experienced (Table 1), left atrial enlargement defined by Morris index [4] was frequent, but the magnitude of the P-wave abnormality was minimal when compared to the two juvenile HCM patients described in this report. It may be that adult HCM patients usually develop atrial fibrillation $[9,10]$ before reaching such prominent bi-atrial enlargement on ECG. Comparative study between juvenile and adult HCM patients using a large sample size is required to confirm the possibility of inherent predisposition to extreme atrial enlargement/hypertrophy causing prominent $\mathrm{P}$-waves on ECGs in juvenile HCM patients.

Table 1. Summary of ECG findings in 24 adult HCM patients.

\begin{tabular}{|c|c|c|c|}
\hline & $\begin{array}{l}\text { Sinus rhythm without history } \\
\text { of heart failure }(\mathrm{N}=12)\end{array}$ & $\begin{array}{l}\text { Paroxismal atrial fibrillation and/or } \\
\text { history of heart failure }(\mathrm{N}=12)\end{array}$ & Total $(\mathrm{N}=24)$ \\
\hline Left atrial enlargement & $1(8 \%)$ & $6(50 \%)$ & $7(29 \%)$ \\
\hline Morris index (mV-sec) & -0.12 & $-0.07 \pm 0.03(-0.04--0.12)$ & $-0.08 \pm 0.03(-0.04--0.12)$ \\
\hline Amplitude (mV) & -1.5 & $-1.17 \pm 0.41(-1--2)$ & $-1.21 \pm 0.39(-1--2)$ \\
\hline Duration (sec) & 0.08 & $0.06 \pm 0.02(0.04-0.08)$ & $0.06 \pm 0.02(0.04-0.08)$ \\
\hline Right atrial enlargement & 0 & 0 & 0 \\
\hline Repolarization abnormalities (ST-T) & $10(83 \%)$ & $11(92 \%)$ & $21(88 \%)$ \\
\hline Left ventricular hypertrophy & $7(58 \%)$ & $5(42 \%)$ & $12(50 \%)$ \\
\hline Right ventricular hypertrophy & $2(17 \%)$ & 0 & $2(8 \%)$ \\
\hline Abnormal Q waves & $1(8 \%)$ & $3(33 \%)$ & $5(21 \%)$ \\
\hline \multicolumn{4}{|l|}{ Conduction disturbance } \\
\hline Left bundle branch block & 0 & $2(17 \%)$ & $2(8 \%)$ \\
\hline Left bundle branch block & $1(8 \%)$ & $2(17 \%)$ & $3(13 \%)$ \\
\hline
\end{tabular}

\footnotetext{
* $=$ ECG recording during sinus rhythm.
} 
(a)

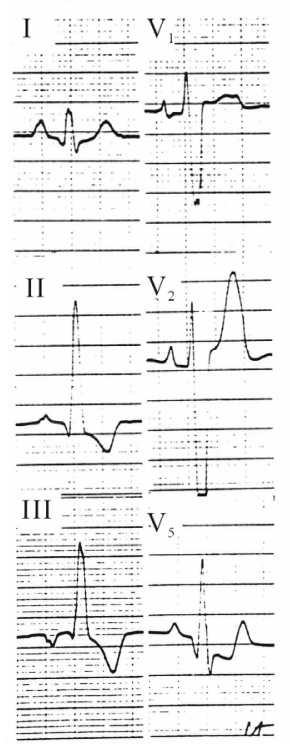

(b)

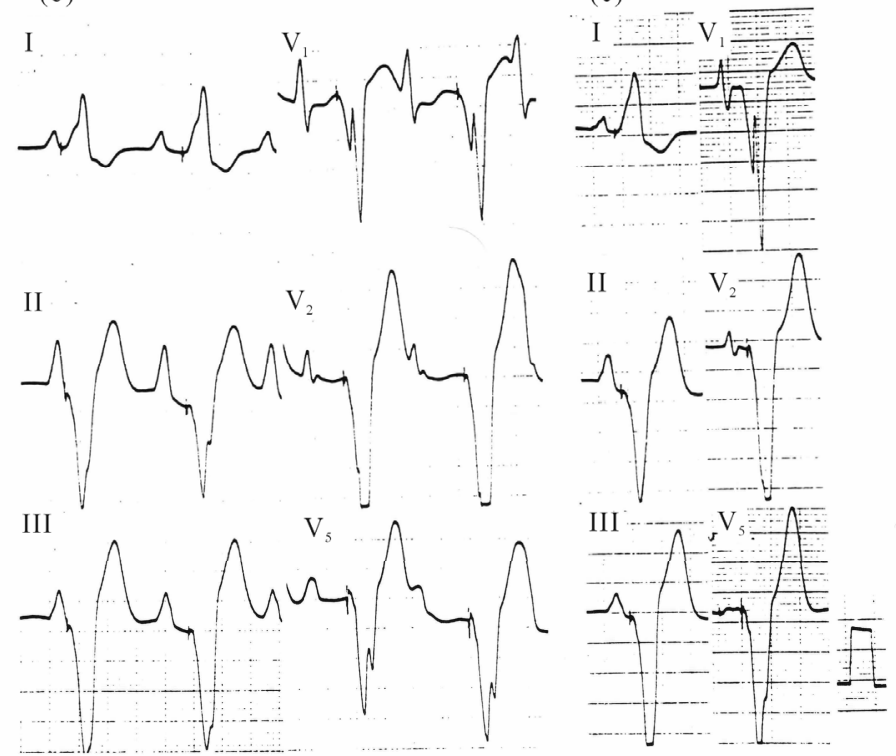

Figure 2. Standard 12-lead ECG of Case No. 2.

\section{CONCLUSION}

Based on the ECG findings, this case report suggested that inherent predisposition to extreme enlargement and/ or hypertrophy may exist in atrial myocardium in juvenile HCM patients.

\section{REFERENCES}

[1] Maron, B.J., Spirito, P., Wesley, Y. and Arce, J. (1986) Development and progression of left ventricular hypertrophy in children with hypertrophic cardiomyopathy: Identification by two-dimensional echocardiography. The New England Journal of Medicine 315, 610-614. doi:10.1056/NEJM198609043151003

[2] Spirito, P. and Maron, B.J. (1989) Relation between extent of left ventricular hypertrophy and age in hypertrophic cardiomyopathy. Journal of the American College of Cardiology, 13, 820-823. doi:10.1016/0735-1097(89)90222-2

[3] Savage, D.D., Seides, S.F., Clark, C.E., Henry, W.L., Maron, B.J., Robinson, F.C. and Epstein, S.E. (1978) Electrocardiographic findings in patients with obstructive and nonobstructive hypertrophic cardiomyopathy. Circulation, 58, 402-408.

[4] Morris, J.J. Jr., Estes, E.H. Jr., Whalen, R.E., Thompson, H.K. Jr. and McIntosh, H.D. (1964) P-wave analysis in valvular heart disease. Circulation, 29, 242-252.

[5] Maron, B.J., Henry, W.L., Clark, C.E., Redwood, D.R., Roberts, W.C. and Epstein, S.E. (1976) Asymmetric sep- tal hypertrophy in childhood. Circulation, 53, 9-19.

[6] McKenna, W., Deanfield, J., Faruqui, A., England, D., Oakley, C. and Goodwin, J. (1981) Prognosis in hypertrophic cardiomyopathy: Role of age and clinical, electrocardiographic and hemodynamic features. American Journal of Cardiology, 47, 532-538. doi:10.1016/0002-9149(81)90535-X

[7] Lazzeroni, E., Domenicucci, S., Ten Cate, F.J., Varacca, A., Zoni, A., Francescon, P., Roelandt, J. and Botti, G. (1988) Electrocardiographic abnormalities in hypertrophic cardimyopathy: Its relation to the extent of myocardial hypertrophy. American Journal of Noninvasive Cardiology, 2, 199-204.

[8] Pelliccia, A., Di Paolo, F.M., Corrado, D., Buccolieri, C., Quattrini, F.M., Pisicchio, C., Spataro, A, Biffi, A., Granata, M. and Maron, B.J. (2006) Evidence for efficacy of the Italian national pre-participation screening programme for identification of hypertrophic cardiomyopathy in competitive athletes. European Heart Journal, 27, 2196-2200. doi:10.1093/eurheartj/ehl137

[9] Olivotto, I., Cecchi, F., Casey, S.A., Dolara, A., Traverse, J.H. and Maron, B.J. (2001) Impact of atrial fibrillation on the clinical course of hypertrophic cardiomyopathy. Circulation, 104, 2517-2524. doi:10.1161/hc4601.097997

[10] Köse, S., Aytemir, K., Sade, E., Can, I., Özer, N., Amasyali, B., Aksöyek, S., Övünç, K., Özmen, F., Atalar, E., Işik, E., Kes, S., Demirtaş, E. and Oto, A. (2003) Detection of patients with hypertrophic cardimyopathy at risk for paroxysmal atrial fibrillation during sinus rhythm by P-wave dispersion. Clinical Cardiology, 26, 431-434. doi:10.1002/clc. 4960260910 